\title{
PENGEMBANGAN MESIN PENGURAI SERAT TANDAN KOSONG KELAPA SAWIT (TKKS) UNTUK MENGHASILKAN SERAT MEKANIS
}

\section{The Development of Palm Empty Fruit Bunch (EFB) Fiber Extractor Machine To Produce Mechanical Fiber}

\author{
Junaidi ${ }^{1 *}$, Anwar Kasim $^{2}$ dan Ardinal $^{3}$ \\ 1 Prodi IImu-ilmu Pertanian, Pascasarjana Universitas Andalas, Limau Manis Padang \\ 2 Jurusan Teknologi Pertanian, Fakultas Teknologi Pertanian, Universitas Andalas, Limau Manis Padang. \\ 3 Balai Riset dan Standardisasi Industri Padang, JI. Raya LIK No. 23 Ulu Gadut Padang \\ e-mail : junaidistmp@yahoo.co.id
}

Diterima: 6 April 2016, revisi akhir: 6 Juni 2016 dan disetujui untuk diterbitkan: 13 Juni 2016

\begin{abstract}
ABSTRAK
Pengembangan mesin pengurai serat tandan kosong kelapa sawit dilakukan untuk menghasilkan serat mekanis sebagai penguat papan partikel. Didalam penelitian ini dilakukan perancangan mesin, pembuatan mesin dan evaluasi teknis kinerja mesin. Evaluasi teknis dilakukan pada putaran $600 \mathrm{rpm}$ dan $900 \mathrm{rpm}$ dengan masing-masing putaran 2 kali penguraian, dan masing-masing penguraian 3 ulangan. Dari hasil rancangan mesin didapatkan kapasitas mesin $\pm 200 \mathrm{~kg} / \mathrm{jam}$ dan daya penggerak $5 \mathrm{HP}$. Hasil evaluasi teknis kinerja mesin didapatkan persentase serat dan serat campuran pada putaran $900 \mathrm{rpm}$ pada pengujian 1 dan 2 tidak berbeda jauh dengan pengujian pada putaran $600 \mathrm{rpm}$. Dari $10 \mathrm{~kg}$ TKKS cacahan masingmasing putaran, didapatkan rata-rata serat bersih $82 \%$, serat campuran $14 \%$, dan $4 \%$ menjadi debu. Dari hasil penguraian pada putaran $600 \mathrm{rpm}$ dan $900 \mathrm{rpm}$ didapatkan 5 macam komposisi tingkatan serat yaitu, a) serat bersih $600 \mathrm{rpm}, \mathrm{b}$ ) serat bersih $900 \mathrm{rpm}, \mathrm{c}$ ) serat campuran (2-3 $\mathrm{cm}+$ kelopak), d) serat campuran ( $<2 \mathrm{~cm}+$ kelopak), e) serat campuran (serat halus + serbuk). Hasil analisis kimia ke lima serat tersebut yaitu, rata-rata kadar air serat 9,3\%, kadar ekstraktif $5,6 \%$, kadar lemak 1,4\%, kadar lignin 33,1\%, kadar holoselulosa 58,33\%, dan selulosa $39,2 \%$. Dibandingkan dengan serat kayu daun jarum dan kayu meranti merah, kandungan kimia serat tersebut hampir sama atau tidak berbeda jauh.
\end{abstract}

Kata Kunci: Mesin pengurai, papan partikel, serat mekanis, tandan kosong kelapa sawit

\begin{abstract}
The purpose of this research was to design shredded oil palm empty fruit bunch (EFB) fiber extractor machine, to conduct technical evaluation on the machine performance, and to conduct fiber chemical analysis. This prototype is expected to increase added value on EFB waste as it is not maximally utilized. The machine must be both technically and economically feasible to be applied in particle board industry to produce oil palm empty fruit bunch fiber. Based on its design, the machine has $\pm 200 \mathrm{~kg} / \mathrm{hours}$ capacity and $5 \mathrm{HP}$ motor. The evaluation of machine performance on 600 RPM and 900 RPM rotations resulted on similar numbers of fiber and mixed fiber percentage. From 10 shredded EFB extracted, $7.6 \mathrm{~kg}(76 \%)$ clean fiber, $2.05 \mathrm{~kg}(20 \%)$ mixed fiber, and $1.35 \mathrm{~kg}$ ash were obtained. Three times extracting process on $600 \mathrm{RPM}$ rotation resulted on fiber percentage based on its length as follows: $4.6 \%$ long fiber $(>10 \mathrm{~cm}), 32.3 \%$ medium fiber $(5-10 \mathrm{~cm})$, and $61.4 \%$ short fiber $(2-4 \mathrm{~cm})$. Meanwhile, the percentages on 900 RPM rotation were $0 \%$ of long fiber, $22.37 \%$ of medium fiber, and short fiber of $77.3 \%$. There were five types of composition of extracted fiber level; 1) clean fiber on 600 RPM, 2) clean fiber on 900 RPM, 3) mixed fiber (medium fiber 2-3 cm + petal), 4) mixed fiber (short fiber $<2 \mathrm{~cm}+$ petal), 5) mixed fiber (soft fiber + pollens). The result of chemical analysis showed that those five types of fibers contained $9.3 \%$ water, $5.6 \%$ extractive, $1.4 \%$ fat, $33.1 \%$ lignin, $58.33 \%$ holocellulose, and $39.2 \%$ cellulose contents. Finally the analysis showed that it had a similar chemical composition compared to the fibers of softwood and Red Meranti wood.
\end{abstract}

Keywords: Extractor machine, particle boards, mechanical fiber, oil palm empty bunch 


\section{PENDAHULUAN}

Komoditi kelapa sawit merupakan salah satu andalan komoditi pertanian Indonesia yang pertumbuhannya sangat pesat dan mempunyai peran strategis dalam perekonomian nasional, salah satu hasil olahan kelapa sawit adalah minyak sawit mentah atau Crude Palm Oil (CPO).

Kegiatan pengolahan kelapa sawit menghasilkan limbah, salah satunya adalah limbah tandan kosong yang jumlahnya 30 s/d $35 \%$ dari total berat tandan buah segar yang diproses. Tandan kosong ini biasanya dibakar di tungku bakar, yang menyebabkan udara emisi melebihi baku mutu (Keputusan Menteri Lingkungan Hidup No. 13/MENLH/III/1995). Hal ini seringkali memberikan dampak terhadap kesehatan masyarakat atau lingkungan hidup di sekitar pabrik. Untuk mengurangi dampak emisi dari pembakaran tandan kosong, pihak perusahaan biasanya melakukan penumpukan tandan kosong di perkebunan. Volume tandan kosong yang cukup besar menyebabkan terjadi pencemaran lingkungan, bau yang kurang sedap, perairan di sekitar perkebunan menjadi kotor, dan terjadi pendangkalan perairan.

Kebutuhan kayu oleh manusia terus meningkat, tetapi daya dukung hutan sebagai penghasil kayu sudah mengkhawatirkan, sehingga terjadi kekurangan pasokan kayu. Salah satu cara mensubsitusi penggunaan kayu adalah dengan produk komposit dari bahan-bahan non kayu, contohnya adalah limbah Tandan Kosong Kelapa Sawit (TKKS) ketersediaannya di Indonesia \pm 4.224.027,99 ton dengan kandungan serat $\pm 70 \%$ (Deptan, 2011).

Hasil dari beberapa penelitian, menyatakan serat dari TKKS dapat dijadikan sebagai penguat papan partikel sebagaimana penggunaan kayu. Umi Fathanah, Sofyana (2013) telah meneliti papan partikel dari serat TKKS dengan perekat kulit akasia dan gambir. Subianto (2003) meneliti papan partikel dari serat TKKS dengan perekat fenol formaldehid. Selanjutnya Subianto (2006) juga telah meneliti papan partikel ukuran komersial dari serat TKKS dilapisi serat kayu meranti dan sengon dengan perekat urea formaldehid. Kasim (2002) juga telah meneliti optimasi pembuatan papan partikel memanfaatkan serat TKKS dan polifenol dari gambir. Hasil penelitiannya didapatkan kondisi optimum dengan kerapatan papan $0,8 \mathrm{~g} / \mathrm{cm}^{3}$ dan sebahagian sifat papan telah memenuhi SNI.

Dari uraian diatas nampak bahwa pemanfaatan serat TKKS sebagai bahan baku papan partikel sangat potensial sekali dikembangkan dalam bentuk skala industri karena bahan tersebut sangat banyak tersedia. Walaupun begitu masih banyak kendala yang ada sehingga penerapannya kepada masyarakat belum bisa dilakukan. Kendala tersebut diantaranya dalam proses pengolahan serat.

Teknologi pengolahan serat TKKS terdiri dari beberapa rangkaian unit kerja utama, yaitu dimulai dari proses pencacah TKKS, pengepres TKKS, pengurai serat TKKS, dan proses pengeringan serat dengan kadar air 10\% (Kasim, 2011). Proses penguraian serat TKKS merupakan salah satu proses yang sangat menentukan kapasitas dan bentuk serat, untuk menghasilkan serat TKKS dalam jumlah besar secara cepat dan kontinyu perlu penggunaan mesin pengurai secara mekanis. Tetapi proses ini belum dapat dilakukan karena mesin ini belum ada di pasaran.

Proses penguraian serat TKKS telah dilakukan secara manual dalam skala laboratorium oleh (Kasim, 2002), yaitu serat TKKS diuraikan dengan proses anaerobik secara fermentasi menggunakan microorganisme untuk menguraikan serat dan dengan proses soda menggunakan $\mathrm{NaOH}$. Dari kedua proses ini setelah 4 hari TKKS mudah diserati atau serat-serat sudah mudah dipisahkan secara manual menggunakan tangan. Dari percobaan di lapangan penyeratan TKKS secara manual dengan tangan hanya mampu menghasilkan serat $\pm 15 \mathrm{~kg} / \mathrm{jam}$. Dalam skala industri proses ini kurang efisien karena banyaknya limbah TKKS yang harus ditangani.

Syamani (2006) mengatakan untuk mendirikan industri papan partikel dari serat alam sesuai standard JIS kapasitas produksi papan partikel minimal $20 \mathrm{~m}^{3}$ per hari dan dibutuhkan bahan baku 13,7 ton. Untuk industri papan partikel skala kecil minimal kapasitas produksi $5 \mathrm{~m}^{3}$ maka diperlukan bahan baku serat 3,4 ton/hari. Dengan 
demikian kapasitas kerja secara manual relative sedikit sehingga meningkatkan biaya produksi.

Serat TKKS termasuk serat alam seperti serat rami, serat sabut kelapa, serat sabut buah sawit dan lain-lain. Proses penguraian dan pemisahan serat hampir sama satu sama lainnya. Prinsipnya adalah merobek, menarik, memutus dan menghempaskan bahan baku sabut atau TKKS atau bahan baku serat lainnya. Sehingga ikatan antara serat dan gabusgabus dapat terpisah (Hadi, 2001). Walaupun begitu penggunaan mesin pengurai serat sabut kelapa atau serat rami atau serat alam lainnya belum tentu bisa digunakan untuk menguraikan serat TKKS, hal ini disebabkan struktur dan kekuatan serat TKKS berbeda dengan serat lainnya. Dengan demikian ukuran mesin, bentuk dan susunan pisau pengurai juga ada perbedaan.

Tujuan penelitian ini adalah merekayasa mesin pengurai serat Tandan Kosong Kelapa Sawit (TKKS) cacahan, melakukan evaluasi teknis terhadap kinerja mesin, dan analisa kimia dari serat TKKS.

\section{METODOLOGI PENELITIAN}

Bahan yang digunakan untuk pengembangan mesin pengurai ini adalah : besi siku dengan ukuran $6 \mathrm{~cm} \times 6 \mathrm{~cm} \times 0,4$ $\mathrm{cm}$ untuk pembuatan rangka alat, besi silinder $\varnothing 5 \mathrm{~cm}$ untuk pembuatan poros pengurai, plat strip ukuran $2 \mathrm{~cm} \times 2,5 \mathrm{~cm}$ untuk batang/pisau pengurai, plat lembaran ukuran $120 \mathrm{~cm} \times 240 \mathrm{~cm}$ dengan tebal 0,25 $\mathrm{cm}$ untuk rumah pengurai. Untuk penggerak mesin menggunakan motor listrik $5 \mathrm{HP}$ putaran $1500 \mathrm{rpm}$, pully, dan sabuk $\mathrm{V}$ type $B$. Bahan pengujian yang diuraikan yaitu, TKKS cacahan yang diambli dari pabrik kelapa sawit PT Agro Wiratama di Pasaman Barat Sumatera Barat. Peralatan untuk pengujian kinerja mesin menggunakan stopwach, jangka sorong dan mistar. Untuk melihat struktur permukaan serat hasil penguraian menggunakan alat uji SEM.

Alat/mesin yang digunakan untuk pembuatan dan assembling mesin pengurai antara lain mesin bubut, mesin milling, mesin gerinda, mesin potong, CNC, mesin Scrap, dan mesin bor, mesin las, alat bending plat, alat rol plat.

\section{Metode}

Penelitian dilaksanakan tiga tahap yaitu perancangan mesin, pembuatan mesin dan evaluasi teknis. Secara garis besar tahapan penelitian ini seperti pada Gambar 1.

\section{Perancangan Mesin Pengurai Serat TKKS}

Perancangan prototype mesin meliputi, menghitung kapasitas mesin dan daya mesin. Untuk mendapatkan daya mesin harus diketahui terlebih dahulu tegangan geser satu buah pisau pengurai terhadap serat berdasarkan luas penampang dari pisau. Setelah itu tentukan gaya geser total keseluruhan berdasarkan jumlah pisau pengurai. Selanjutnya adalah perhitungan sabuk dan pully, $\varnothing$ poros pengurai, perhitungan pasak dan bantalan.

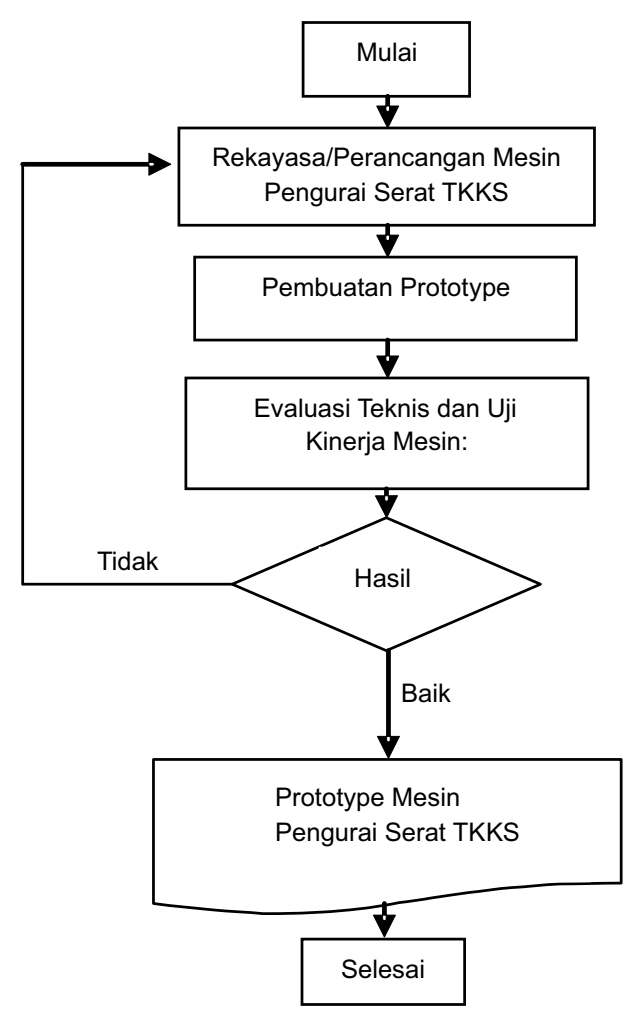

Gambar 1. Diagram Alir Penelitian

Dari perhitungan rancangan mesin didapatkan kapasitas mesin $\pm 200 \mathrm{~kg} / \mathrm{jam}$, putaran poros pencacah $400 \mathrm{rpm}$, daya mesin $\pm 4,5$ HP. Dua buah sabuk yang digunakan adalah sabuk tipe $B$ dengan 
panjang 64 inchi. Diameter poros pengurai $50 \mathrm{~mm}$, bantalan yang digunakan untuk menumpu kedua poros pengurai adalah bantalan rol silindris nomor N312 NU312 (Sularso, 1997 hal 146) dengan spesifikasi, diameter dalam $60 \mathrm{~mm}$, diameter luar 130 $\mathrm{mm}$ dan tebal bantalan $31 \mathrm{~mm}$. Bentuk rancangan mesin seperti Gambar 2.

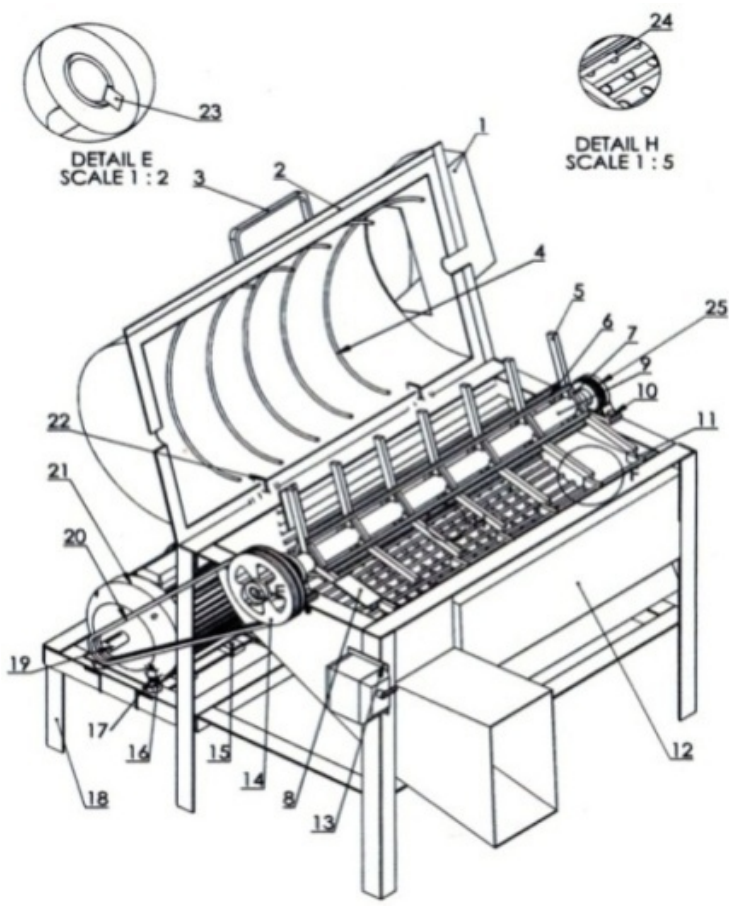

Gambar2. Rancangan Mesin Pengurai Serat TKKS

\section{Keterangan:}

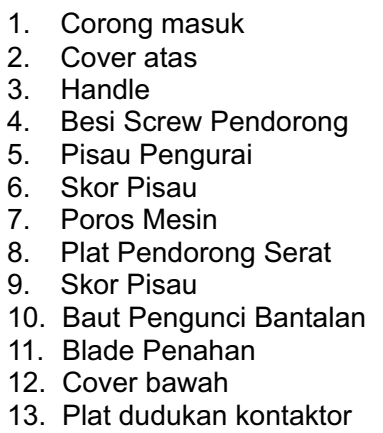

\author{
14. Pully Mesin \\ 15. Baut Pengunci Motor \\ 16. Mur Stelan Motor \\ 17. Baut Stelan Motor \\ 18. Rangka Mesin \\ 19. Pully Motor \\ 20. Belt \\ 21. Motor Penggerak \\ 22. Engsel Mesin \\ 23. Pasak \\ 24. Besi Penahan Serat \\ 25. Bearing
}

Komponen mesin yang telah dirancang seperti pada Gambar 3, 4, 5 dan 6. Beberapa dimensi ukuran komponen unit pengurai pada Gambar 3 yaitu panjang poros pengurai $115,3 \mathrm{~cm}, \varnothing$ poros pengurai $5 \mathrm{~cm}$, jarak antar batang pengurai $13,7 \mathrm{~cm}$, ukuran batang pengurai $2 \mathrm{~cm} \times 2,5 \mathrm{~cm}$. Jumlah pisau/batang pengurai satu lingkaran/unit 3 buah dan sepanjang poros 5 unit. jumlah batang pengurai seluruhnya adalah 15 buah. Pada ujung poros terdapat batang pendorong serat keluar melalui corong keluar berjumlah 3 buah.

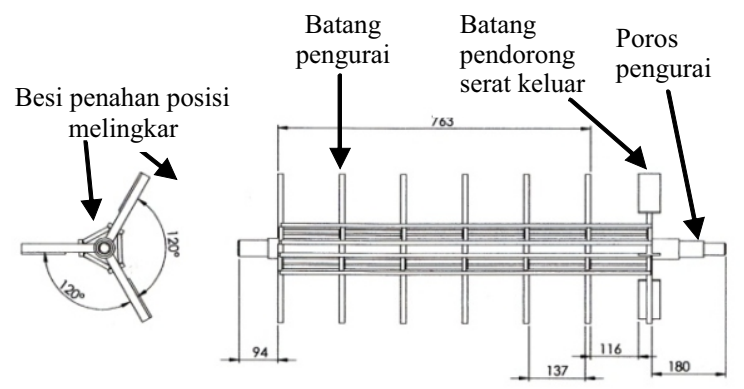

Gambar 3. Unit Komponen Pengurai Serat

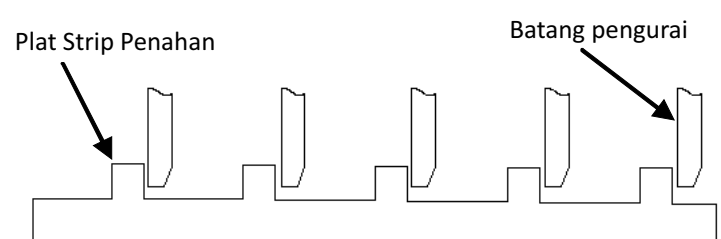

Gambar 4. Komponen Plat Sirip

Pada bagian tengah antara rumah pengurai dan tepi rangka dipasang plat dengan sirip-sirip sebagai komponen penahan bahan TKKS cacahan pada saat pisau/batang pengurai diputar oleh poros pengurai. Sehingga dengan adanya gaya perlawanan dari sirip-sirip ini TKKS cacahan lebih teruraikan. Bentuk komponen plat strip seperti Gambar 4.

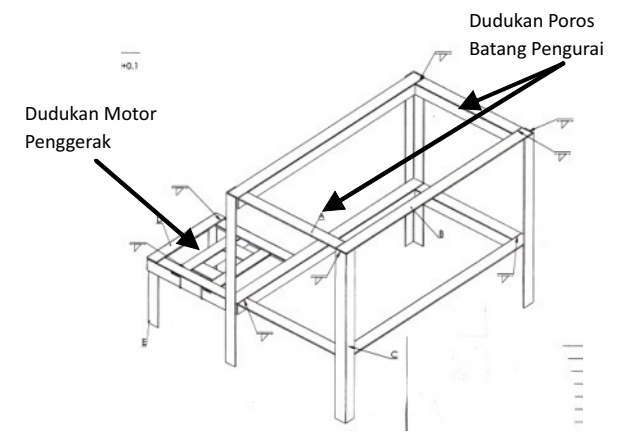

\section{Gambar 5. Rangka Mesin Pengurai}

Rangka mesin terdiri dari rangka dudukan unit pengurai dan rangka dudukan motor penggerak. Rangka ini menggunakan besi siku dengan ukuran $6 \mathrm{~cm} \times 6 \mathrm{~cm}$ dengan tebal $0,4 \mathrm{~cm}$. Ukuran rangka dudukan unit pengurai adalah $70 \mathrm{~cm} \times 80 \mathrm{~cm} \times 40 \mathrm{~cm}$ dan ukuran rangka dudukan motor penggerak adalah $50 \mathrm{~cm} \times 50 \mathrm{~cm} \times 50 \mathrm{~cm}$. Bentuk rangka mesin pengurai serat TKKS seperti pada Gambar 5. 


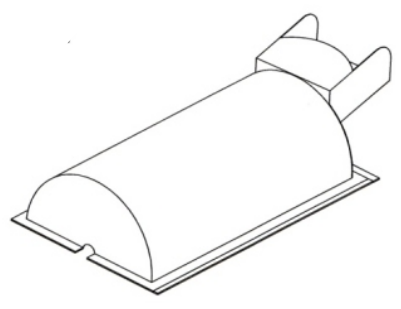

Gambar 6. Tutup Atas Mesin

Pada Gambar 6 tutup atas dari mesin berdiameter $50 \mathrm{~cm}$ dan pada Gambar 7 bentuk tutup bawah. Pada tutup bawah ini terdapat komponen saringan dan corong keluar. Saringan berfungsi untuk mengeluarkan butiran gabus dan serat-serat halus pada saat TKKS cacahan diuraikan oleh batang/pisau pengurai.

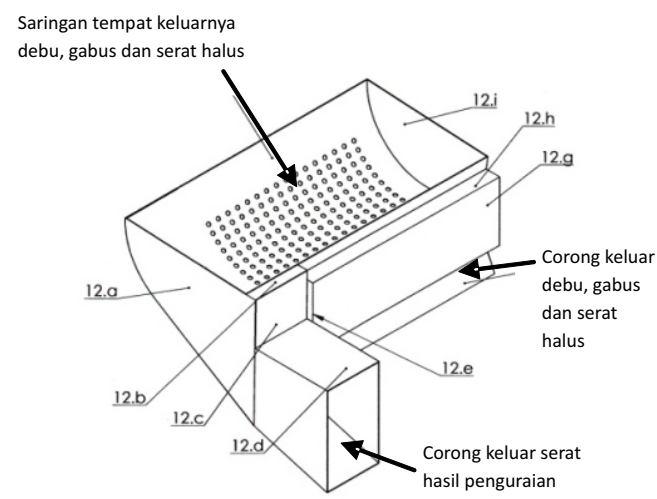

Gambar 7. Tutup Bawah Mesin

\section{Pembuatan Mesin Pengurai Serat TKKS}

Setelah rancangan mesin siap kemudian dilakukan pembuatan komponen dan assembling. Komponen-komponen mesin dipasang berdasarkan unit-unit yang ada pada mesin.

\section{Evaluasi teknis}

Evaluasi kinerja mesin pada putaran 600 rpm dan 900 rpm, tiap putaran dilakukan dua sampel. Tiap sampel penguraian sebanyak 3 kali, 1 sampel sebanyak $10 \mathrm{~kg}$ serat TKKS cacahan. Tiap sampel pada hasil penguraian 1 dihitung berat serat, berat serat campuran, dan berat serat yang tersisa dimesin. Pada penguraian 2, serat bersih pada penguraian 1 diuraikan lagi untuk mendapatkan serat yang lebih bersih. Hasil pada penguraian 2 diantaranya serat bersih, serat campuran dan tersisa dimesin ditimbang beratnya, begitu juga pada penguraian tiga sama dengan penguraian 2 .

Selanjutnya serat campuran pada penguraian 1, 2 dan 3 pada tiap sampel dicampurkan dan kemudian dipisahkan dengan dua saringan dengan diameter lobang yang berbeda. Klasifikasi serat campuran dari hasil penguraian yaitu serat menengah $(3-2 \mathrm{~cm})+$ kelopak, serat pendek $(<2 \mathrm{~cm})+$ kelopak, dan serat halus + kotoran.

Evaluasi teknis kinerja mesin diantaranya: a). Kapasitas mesin

Kapasitas mesin merupakan kemampuan mesin tersebut untuk mengolah bahan persatuan waktu, dengan persamaan:

dimana:

$$
\mathrm{Ce}=\frac{M}{T}
$$

$$
\begin{aligned}
& \mathrm{Ce}=\text { Kapasitas efektif }(\mathrm{kg} / \mathrm{jam}) \\
& \mathrm{M}=\text { Jumlah bahan yang diuraikan }(\mathrm{kg}) \\
& \mathrm{T}=\text { Waktu lamanya penguraian }(\mathrm{jam})
\end{aligned}
$$

b) Persentase serat berdasarkan panjang Persentase berat serat berdasarkan panjang ditentukan dengan mengambil sampel secara acak pada penguraian 1, 2 dan 3 berupa serat sebanyak $\pm 4 \mathrm{~g}$. Klasifikasi ukuran panjang untuk menentukan persentase berat serat adalah: serat panjang $(>10 \mathrm{~cm})$, serat menegah (5$10 \mathrm{~cm})$ dan serat pendek $(2-4 \mathrm{~cm})$. Setelah itu bandingkan berat serat pada masingmasing kelompok dengan berat total sampel yang dikalikan $100 \%$.

\section{c) Karakteristik kimia serat.}

Analisa kimia yang dilakukan terhadap serat dengan cara mengambil serat TKKS secara acak dan menimbangnya. Pengamatan yang dilakukan terhadap serat adalah analisis kadar air, kadar ekstraktif, kadar lemak, kadar lignin, kadar holoselulosa dan kadar selulosa. 


\section{HASIL DAN PEMBAHASAN}

\section{Hasil Pengujian Kinerja Mesin}

Dari hasil pengujian kinerja mesin didapatkan data hasil pengujian pada putaran $600 \mathrm{rpm}$ dan $900 \mathrm{rpm}$ dengan $10 \mathrm{~kg}$ TKKS cacahan seperti pada Tabel 1,2,3, 4 dan 5.

Tabel 1. Data Hasil Penguraian serat TKKS Cacahan pada Putaran 600 rpm

\begin{tabular}{|c|c|c|c|c|c|c|}
\hline \multirow{2}{*}{$\begin{array}{c}\text { Pengu- } \\
\text { jian }\end{array}$} & $\begin{array}{c}\text { Pengu- } \\
\text { raian } \\
\text { ke- }\end{array}$ & \multicolumn{3}{|c|}{ Hasil Penguraian } & \multirow{2}{*}{$\begin{array}{c}\text { Waktu } \\
\text { serat (kg) }\end{array}$} & $\begin{array}{c}\text { Kapasitas } \\
\text { (Kg/jam) }\end{array}$ \\
\cline { 3 - 5 } & Serat & $\begin{array}{c}\text { Serat } \\
\text { Campuran }\end{array}$ & $\begin{array}{c}\text { Sisa } \\
\text { mesin }\end{array}$ & & \\
\hline \multirow{3}{*}{ I } & I & 7,6 & 2,05 & 0,2 & 6,9 & 66 \\
& II & 6,5 & 0,74 & 0,2 & 6,7 & 58,2 \\
& III & 5,7 & 0,5 & 0,2 & 4,5 & 76 \\
\hline \multirow{2}{*}{ II } & I & 7,9 & 1,8 & 0,17 & 8,9 & 53 \\
& II & 6,6 & 1 & 0,2 & 8,23 & 48 \\
& III & 5,9 & 0,7 & 0,3 & 7,30 & 48,5 \\
\hline
\end{tabular}

Tabel2. Data Hasil Pemisahan Serat Campuran pada Putaran 600 rpm

\begin{tabular}{|c|c|c|c|}
\hline \multirow{3}{*}{ Pengujian } & \multicolumn{3}{|c|}{ Serat Campuran (kg) } \\
\cline { 2 - 4 } & $\begin{array}{c}\text { Serat Menengah } \\
(3-2 \mathrm{~cm})+\text { Kolopak }\end{array}$ & $\begin{array}{c}\text { Serat pendek } \\
(<2 \mathrm{~cm})+ \\
\text { Kelopak }\end{array}$ & $\begin{array}{c}\text { serat } \\
\text { halus + } \\
\text { kotoran }\end{array}$ \\
\hline $\mathrm{I}$ & 1,1 & 0,9 & 1,55 \\
$\mathrm{II}$ & 1,15 & 0,8 & 1,2 \\
\hline
\end{tabular}

Tabel3. Hasil Penguraian serat TKKS Cacahan 900 rpm

\begin{tabular}{|c|l|c|c|c|c|c|}
\hline \multirow{2}{*}{$\begin{array}{c}\text { Pengu- } \\
\text { jian }\end{array}$} & \multirow{2}{*}{$\begin{array}{c}\text { Pengu- } \\
\text { raian } \\
\text { ke- }\end{array}$} & \multicolumn{3}{|c|}{ Hasil Penguraian } & \multirow{2}{*}{$\begin{array}{c}\text { Werat (kg) } \\
\text { (menit) }\end{array}$} & $\begin{array}{c}\text { Kapasitas } \\
\text { (Kg/jam) }\end{array}$ \\
\cline { 3 - 5 } & Serat & $\begin{array}{c}\text { Serat } \\
\text { campuran }\end{array}$ & $\begin{array}{c}\text { Sisa } \\
\text { mesin }\end{array}$ & & 12,34 \\
\hline \multirow{3}{*}{ I } & I & 7,2 & 1,2 & 0,5 & 35 & 12,8 \\
& II & 5,82 & 0,65 & 0,6 & 27,30 & 10,3 \\
& III & 5 & 0,61 & 0,6 & 29,14 & 13 \\
\hline \multirow{3}{*}{ II } & I & 7,6 & 1,4 & 0,53 & 34,12 & 13,36 \\
& II & 6,0 & 0,4 & 0,3 & 32,32 & 11,13 \\
& III & 5 & 0,43 & 0,35 & 34,40 & 8,72 \\
\hline
\end{tabular}

Tabel 4. Hasil Pemisahan Serat Campuran pada putaran $900 \mathrm{rpm}$

\begin{tabular}{|c|c|c|c|c|}
\hline \multirow{2}{*}{$\begin{array}{c}\text { Putaran } \\
\text { (RPM) }\end{array}$} & $\begin{array}{c}\text { Pengu- } \\
\text { jian }\end{array}$ & $\begin{array}{c}\text { Senat } \\
\text { Mengah (3- } \\
2 \mathrm{~cm})+ \\
\text { Kolopak }\end{array}$ & $\begin{array}{c}\text { Serat pendek } \\
(<2 \mathrm{~cm})+ \\
\text { Kelopak }\end{array}$ & $\begin{array}{c}\text { serat } \\
\text { halus + } \\
\text { kotoran }\end{array}$ \\
\hline 900 & $\mathrm{I}$ & 1,25 & 0,82 & 1,65 \\
$\mathrm{II}$ & 1,22 & 0,9 & 1,60 \\
\hline
\end{tabular}

\section{(1) Kapasitas Mesin}

Pada Tabel 1 terlihat rata-rata kapasitas mesin pada putaran $600 \mathrm{rpm}$ pada pengujian 1 adalah $66,7 \mathrm{~kg} / \mathrm{jam}$ dan pada pengujian 2 adalah 49,8 kg/jam. Sedangkan kapasitas mesin pada putaran 900 RPM pada pengujian 1 (Tabel 3 ) adalah 11,81 $\mathrm{kg} / \mathrm{jam}$, dan pada pengujian 2 adalah 11 $\mathrm{kg} / \mathrm{jam}$. Penurunan kapasitas mesin pada putaran 900 rpm karena beban kerja mesin terlalu besar, akibatnya batang-batang pengurai kurang mampu menahan tekanan dari plat penahan, sehingga jarak clearence antara ujung tepi batang pengurai dengan tepi plat penahan menjadi besar. Dengan semakin besarnya jarak clearence tersebut proses penguraian kurang sempurna. Untuk mengatasi hal tersebut proses pemasukan bahan diperlambat, akibatnya waktu menjadi lama dan sekaligus kapasitas kecil.

\section{(2) Jumlah Serat dan Serat Campuran yang dihasilkan}

Pada Tabel 1 dengan putaran 600 rpm, pengujian 1 dan penguraian 1 dari $10 \mathrm{~kg}$ TKKS cacahan yang seratnya diuraikan didapatkan serat bersih $7,6 \mathrm{~kg}(76 \%)$, serat campuran $2,05 \mathrm{~kg}(20 \%)$ dan $0,35 \mathrm{~kg}(3,5 \%)$ sisa dimesin dan menjadi debu. Pada penguraian ke 2 dan ke 3 serat yang dihasilkan semakin bersih, jumlah serat campuran semakin sedikit. Begitu juga pada pengujian 2 persentase serat dan serat campuran tiap kali penguraian hampir sama. Persentase serat dan serat campuran pada putaran $900 \mathrm{rpm}$ pada pengujian 1 dan 2 (Tabel 3) juga tidak berbeda jauh dengan pengujian pada putaran $600 \mathrm{rpm}$. Pada pengujian 1 dan penguraian 1 pada putaran $900 \mathrm{rpm}$, didapatkan serat bersih $7,2 \mathrm{~kg}$ (72\%), serat campuran $1,2 \mathrm{~kg}(12 \%)$ dan 1,6 $\mathrm{kg}(16 \%)$ sisa dimesin dan menjadi debu. Dari 3 kali proses penguraian pada kedua putaran tersebut (Tabel 2 dan Tabel 4) didapatkan beberapa tingkatan serat campuran yaitu, 1$)$ serat menengah $(3-2 \mathrm{~cm})$ + kelopak, 2) serat pendek ( $<2 \mathrm{~cm})+$ kelopak, 3) serat halus + serbuk.

Bentuk serat dan serat campuran pada penguraian $600 \mathrm{rpm}$ dan $900 \mathrm{rpm}$ seperti pada Gambar 8, 9, 10, dan 11.

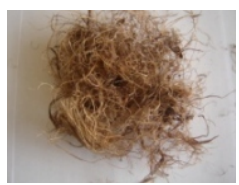

a

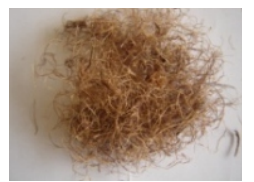

b

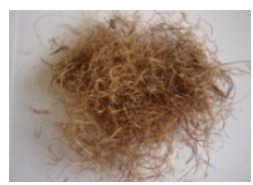

C
Gambar 8. Serat bersih putaran $600 \mathrm{rpm}$

Keterangan:

8a. Serat pada ulangan 1

8 b. Serat pada ulangan 2

$8 c$. Serat pada ulangan 3 


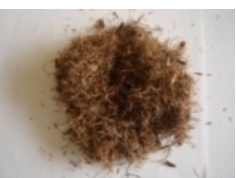

a

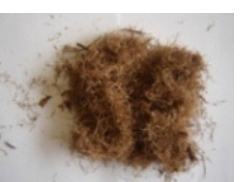

b

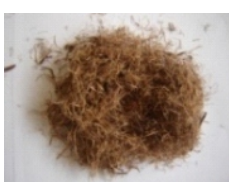

C
Gambar9. Serat Campuran putaran 600 rpm

Keterangan :

9a. Serat campuran pada ulangan 1

9b. Serat campuran pada ulangan 2

9c. Serat Campuran pada ulangan 3

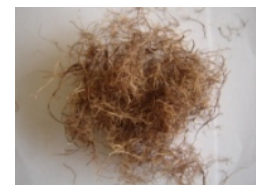

a

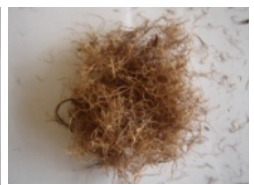

b

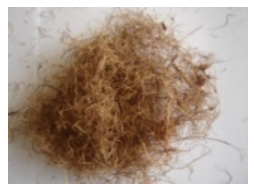

C
Gambar 10. Serat bersih putaran 900 rpm Keterangan:

10a. Serat pada ulangan 1

10b. Serat pada ulangan 2

10c. Serat pada ulangan 3

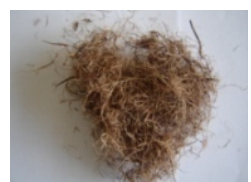

a

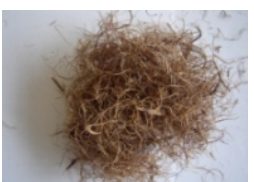

b

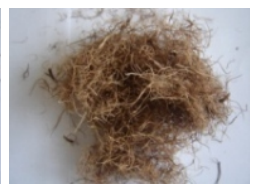

C
Gambar11. Serat campuran putaran 900 rpm

Keterangan :

11a. Serat campuran pada ulangan 1

11b. Serat campuran pada ulangan 2

11c. Serat campuran pada ulangan 3

Agar bentuk serat lebih jelas bedanya maka dilakukan foto uji dengan alat SEM untuk melihat struktur permukaan serat pada putaran $600 \mathrm{rpm}, 900 \mathrm{rpm}$ dan serat campuran, kemudian dibandingkan dengan serat yang diuraikan secara manual dengan tangan. Bentuk struktur permukaan serat tersebut seperti pada Gambar 12, 13, 14 dan 15.

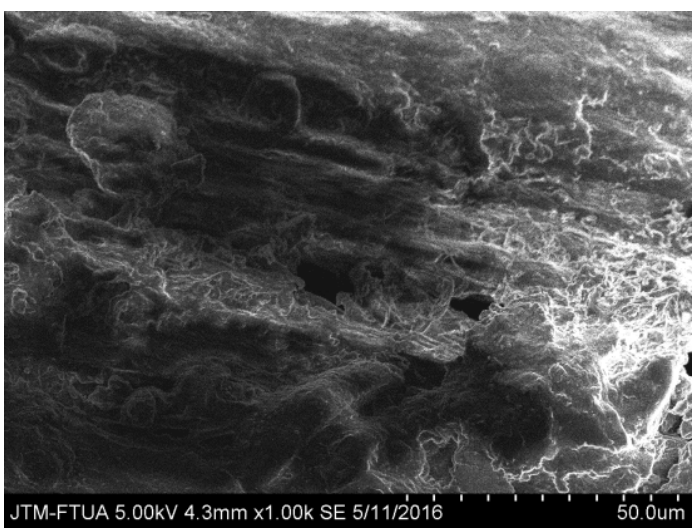

Gambar 12. Struktur permukaan serat dengan penguraian secara manual.

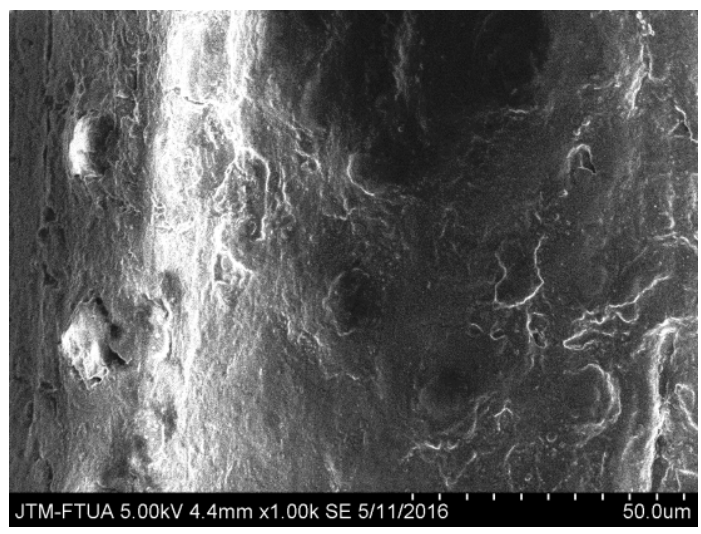

Gambar 13. Struktur permukaan serat pada putaran $600 \mathrm{rpm}$

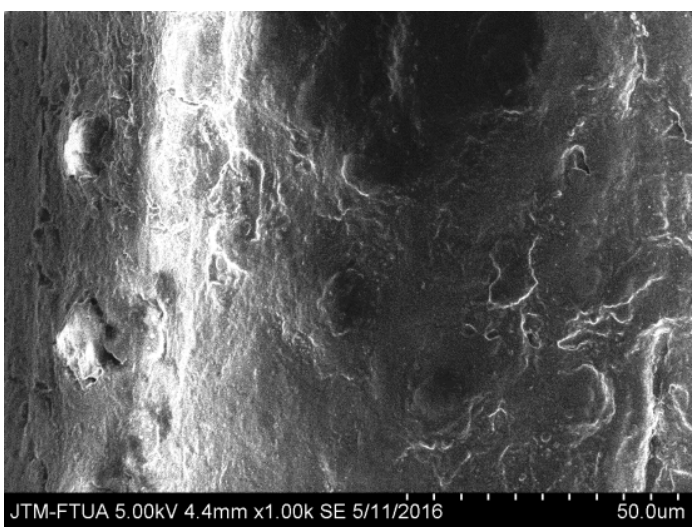

Gambar 14. Struktur permukaan serat pada putaran 900 rpm 


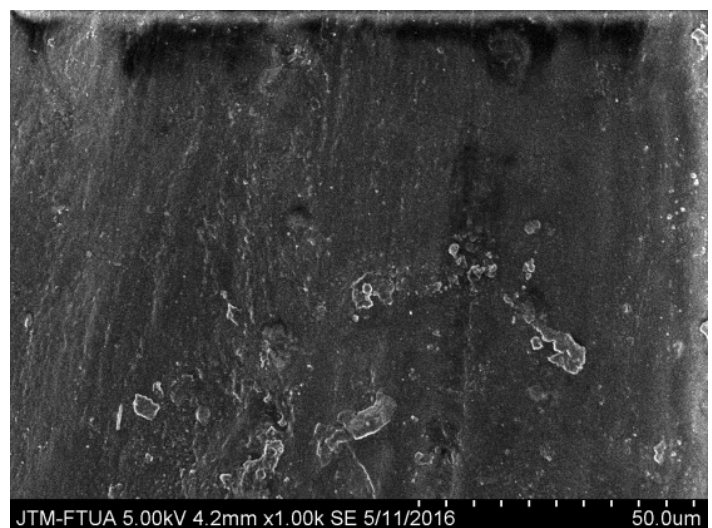

Gambar 15. Struktur permukaan serat campuran

Pada Gambar 12, permukaan serat (kulit luar serat) terdapat lapisan yang menempel dengan rongga-rongga yang tidak beraturan. Lapisan tersebut terdiri dari lignin yang membuat serat menjadi kaku dan mudah patah. Dengan proses permesinan untuk menguraikan serat, maka lapisanlapisan yang menempel itu akan dikikis dan serat lebih elastis. Pada Gambar 13, lapisan yang menempel pada kulit luar serat sudah banyak yang terkikis, rongga-rongga serat sangat sedikit. Pada Gambar 14, permukaan luar serat sudah bersih, dan lapisan yang menempel sudah habis dan serat sangat elastis. Selanjutnya pada Gambar 15 lapisan luar serat juga sudah terkikis dan permukaan luar serat bersih dan tidak berongga.

\section{(1) Persentase hasil serat Berdasarkan panjang}

Tabel5. Persentase Hasil Serat Berdasarkan Panjang $3 \times$ Proses Penguraian

\begin{tabular}{|c|c|c|c|c|c|c|}
\hline $\begin{array}{l}\text { Puta- } \\
\text { ran }\end{array}$ & $\begin{array}{c}\text { Pengu- } \\
\text { jian } \\
\text { ke }\end{array}$ & $\begin{array}{c}\text { Pengu- } \\
\text { raian }\end{array}$ & $\begin{array}{l}\text { Jumlah } \\
\text { sample } \\
\text { (g) }\end{array}$ & $\begin{array}{c}\text { Ukuran } \\
\text { (cm) }\end{array}$ & Berat (g) & $\begin{array}{c}\text { Persentase } \\
(\%)\end{array}$ \\
\hline \multirow{18}{*}{600} & \multirow{9}{*}{ I } & \multirow{3}{*}{1} & \multirow{3}{*}{4,05} & $>10 \mathrm{~cm}$ & 0,33 & 8,1 \\
\hline & & & & $5-10 \mathrm{~cm}$ & 1,19 & 29,4 \\
\hline & & & & $2-4 \mathrm{~cm}$ & 2,46 & 60 \\
\hline & & \multirow{3}{*}{ II } & \multirow{3}{*}{4,06} & $>10 \mathrm{~cm}$ & 0,25 & 6,1 \\
\hline & & & & $5-10 \mathrm{~cm}$ & 1,44 & 35,4 \\
\hline & & & & $2-4 \mathrm{~cm}$ & 2,32 & 57 \\
\hline & & \multirow{3}{*}{ III } & \multirow{3}{*}{4,1} & $>10 \mathrm{~cm}$ & 0,19 & 4,6 \\
\hline & & & & $5-10 \mathrm{~cm}$ & 1,33 & 32,4 \\
\hline & & & & $2-4 \mathrm{~cm}$ & 2,57 & 62,6 \\
\hline & \multirow{9}{*}{ II } & \multirow{4}{*}{ I } & \multirow{3}{*}{3,9} & $>10 \mathrm{~cm}$ & 0,1 & 2,5 \\
\hline & & & & $5-10 \mathrm{~cm}$ & 1,21 & 31 \\
\hline & & & & $2-4 \mathrm{~cm}$ & 2,41 & 61,8 \\
\hline & & & \multirow{3}{*}{4,0} & $>10 \mathrm{~cm}$ & 0,13 & 3,2 \\
\hline & & \multirow[t]{2}{*}{ II } & & $5-10 \mathrm{~cm}$ & 1,15 & 28,7 \\
\hline & & & & $2-4 \mathrm{~cm}$ & 2,75 & 68,7 \\
\hline & & \multirow{3}{*}{ III } & \multirow{3}{*}{3,34} & $>10 \mathrm{~cm}$ & 0,12 & 3,6 \\
\hline & & & & $5-10 \mathrm{~cm}$ & 1,22 & 36,5 \\
\hline & & & & $2-4 \mathrm{~cm}$ & 1,95 & 58,4 \\
\hline
\end{tabular}

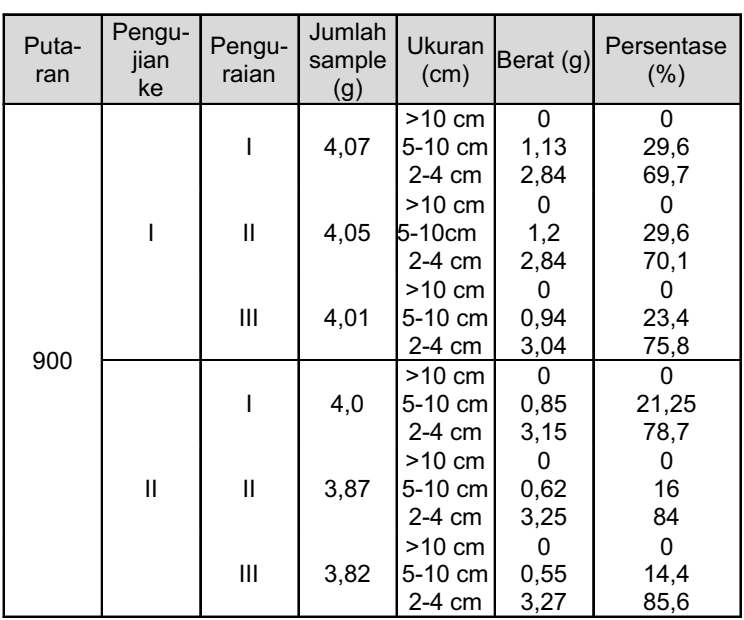

Pada Tabel 5 hasil penguraian TKKS cacahan didapatkan serat bersih pada putaran 600 dan $900 \mathrm{rpm}$ dengan 3 ukuran serat yaitu, serat panjang $>10 \mathrm{~cm}$, serat menengah $5-10 \mathrm{~cm}$ dan serat pendek $2-4$ $\mathrm{cm}$.

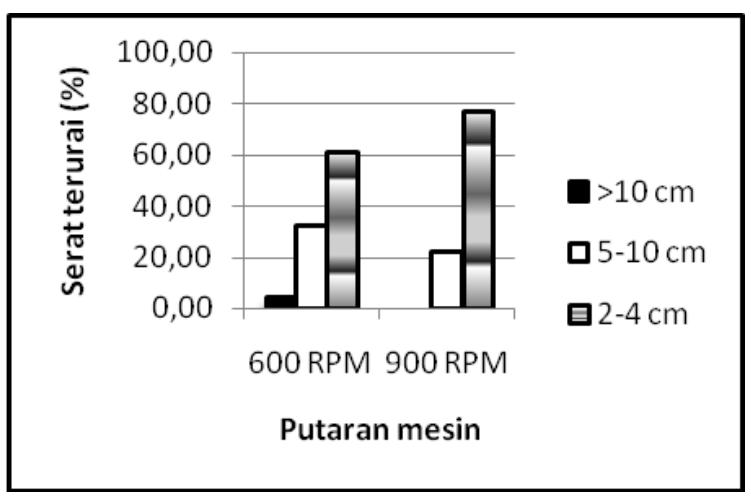

Gambar 16. Persentase Serat Terurai Berdasarkan Panjang Serat

Persentase serat berdasarkan panjang serat seperti pada Gambar 16. Persentase serat panjang $(>10 \mathrm{~cm})$, menengah $(5-10$ $\mathrm{cm})$, dan pendek $(2-4 \mathrm{~cm})$ pada pengujian 1 dan 2 dengan putaran 600 rpm rata-rata $4,6 \%, 32,2 \%$ dan $61,4 \%$, sedangkan pada putaran $900 \mathrm{rpm}$ persentase serat panjang $0 \%$, serat menengah $22,37 \%$ dan serat pendek $77,3 \%$. Perbandingan serat menengah dan serat pendek pada putaran $600 \mathrm{rpm}$ hampir 1:2, dan sedikit serat panjang. Pada putaran $900 \mathrm{rpm}$ tidak ada ukuran serat panjang, jumlah serat pendek sangat besar sekali dibandingkan serat menengah. Hal ini disebabkan semakin banyak putaran dari mesin, maka semakin sering terjadinya pemutusan serat, sehingga serat semakin pendek. 
Berdasarkan hasil pengujian mesin pengurai serat TKKS pada putaran $600 \mathrm{rpm}$ dan 900 rpm, maka didapatkan 5 macam komposisi tingkatan serat hasil penguraian yaitu, a) serat bersih $600 \mathrm{rpm}, \mathrm{b}$ ) serat bersih $900 \mathrm{rpm}, \mathrm{c}$ ) serat campuran (serat menengah 2-3 cm+kelopak), d) serat campuran (serat pendek $<2 \mathrm{~cm}+$ kelopak), e) serat campuran (serat halus + serbuk). Kelima tingkatan serat ini nantinya akan digunakan sebagai bahan baku papan komposit dengan terlebih dahulu harus diketahui kandungan kimia seratnya, apakah memenuhi syarat untuk digunakan sebagai bahan baku papan partikel.

\section{Karakteristik Kimia Serat}

Berdasarkan hasil analisis kimia terhadap 5 komposisi tingkatan serat TKKS hasil penguraian mekanis dapat dilihat pada Tabel 6.

Tabel6. Hasil analisis kimia terhadap komposisi tingkatan serat hasil penguraian mekanis

\begin{tabular}{lccccc}
\hline \multirow{2}{*}{ Analisis } & \multicolumn{5}{c}{ Komposisi Tingkatan serat } \\
\cline { 2 - 6 } & a & b & c & d & e \\
\hline Kadar air (\%) & 9,59 & 9,78 & 9,80 & 8,80 & 8,40 \\
Kadar Ekstraktif (\%) & 6,51 & 6,49 & 5,53 & 4,63 & 5,07 \\
Kadar lemak (\%) & 1,53 & 1,84 & 1,89 & 0,55 & 1,32 \\
Kadar lignin (\%) & 36,49 & 24,8 & 34,9 & 33,3 & 36,1 \\
Kadar holoselulosa & 46,18 & 57,03 & $60,5765,27$ & 62,62 \\
(\%) & 29,81 & 37,63 & $39,3944,62$ & 44,52 \\
Kadar selulosa (\%) & 29,84 \\
\hline
\end{tabular}

\section{Keterangan:}

Serat $\mathrm{a}=$ serat campuran (serat halus + serbuk)

Serat $b=$ serat campuran (serat $1-2 \mathrm{~cm}+$ kelopak)

Serat $c=$ serat campuran (serat $2-3 \mathrm{~cm}+$ kelopak),

Serat $\mathrm{d}=$ serat bersih pengujian $900 \mathrm{rpm}$

Serat $\mathrm{e}=$ serat bersih pengujian $600 \mathrm{rpm}$

Sebagai bahan perbandingan, pada Tabel 7 dapat dilihat kandungan kimia serat kayu daun jarum dan kayu daun lebar.

Tabel7. Kandungan kimia serat kayu daun jarum dan kayu daun lebar

\begin{tabular}{lcc}
\hline \multicolumn{1}{c}{ Komponen } & Daun jarum & Meranti merah \\
\hline Kadar Ekstraktif (\%) & 5,00 & - \\
Kadar lignin (\%) & 27,90 & 33,00 \\
Kadar holoselulosa (\%) & 53,59 & 62,86 \\
Kadar selulosa (\%) & 42,59 & 50,70 \\
\hline
\end{tabular}

Sumber: Atlas Kayu Indonesia (Martawijaya et al, 1989
Pada Tabel 6 dapat dilihat kadar air serat $a, b, c, d$, dan e berturut-turut $9,59 \%$, $9,78 \%, 9,80 \%, 8,80 \%$ dan 8,40\%. Kadar air serat sebagai bahan baku papan partikel akan mempengaruhi terhadap kadar air papan partikel. Haygreen dan Bowyer (1993) menjelaskan apabila dalam pembuatan papan serat menggunakan perekat cair, maka partikel yang digunakan harus kering (2\%-5\%), karena dengan ditambahnya perekat maka kadar air papan akan bertambah sekitar $4-6 \%$ sehingga kandungan air akhir mendekati $10 \%$.

Kadar ekstraktif akan mempengaruhi terhadap kekuatan geser (Modulus of Rupture) dan pengembangan tebal papan partikel yang dihasilkan. Pada Tabel 6 diatas kadar zat ekstraktif bahan serat khususnya bahan serat (d) dan (e) hampir sama dengan kadar zat ekstraktif serat kayu daun jarum. Kadar zat ekstraktif pada serat TKKS sebagian besar adalah minyak/lemak. Kadar minyak yang tinggi akan memberikan pengaruh negatif terhadap proses perekatan (Sutigno, 1988). Pada Tabel 6, kadar lemak dari kelima komposisi tingkatan serat tersebut diatas berturut-turut adalah 1,53\%, $1,84 \%, 1,89 \%, 0,55 \%$ dan $0,32 \%$. Kadar lemak serat tersebut sangat kecil sekali dibandingkan dengan standar SNI yang mengizinkan kadar lemak serat sebagai bahan baku papan partikel maximal 3\% (Hidayati, 1989 cit Propatria, 2000). Rendahnya kadar lemak serat karena perlakuan mekanis bahan TKKS mulai dari proses pencincangan, pengepresan sampai proses penguraian/pemisahan serat. Pada putaran mesin $900 \mathrm{rpm}$, kadar lemak serat (bahan d) adalah 0,55\%, dan pada putaran $600 \mathrm{rpm}$ kadar lemak serat (bahan e) adalah $1,32 \%$. Sedangkan serat pada bahan (a), (b) dan (c) merupakan kotoran dari hasil proses pemisahan TKKS cacahan kedua putaran mesin tersebut. Ketiga bahan tersebut masih bisa digunakan sebagai bahan baku papan partikel karena kadar lemaknya kecil dari $3 \%$. Namun demikian serat bahan (d) dan (e) sangat potensial sekali digunakan sebagai bahan baku papan partikel karena kadar lemaknya sangat kecil, dan bahan serat (d) adalah kadar lemaknya yang paling kecil.

Kadar holoselulosa dan selulosa dari kelima bahan serat tersebut sangat tinggi 
sekali khususnya pada bahan serat (c), (d) dan (e), dan juga pada ketiga bahan tersebut kadar holoselulosa dan selulosa hampir sama dengan bahan serat daun jarum dan meranti merah pada Tabel 7. Menurut Haroen et al (1985) cit Propatria (2000), selulosa dan holoselulosa memiliki afinitas besar terhadap air sehingga memudahkan pembentukan ikatan antar serat dan menyempurnakan kontak antar serat. Ditambahkan oleh Sudrajat (1979) cit Suri (2002), holoselulosa dan selulosa terdiri dari bagian amorf dan kristalit. Bagian kristalit sangat menentukan kekerasan dan kekuatan papan partikel.

Selanjutnya kadar lignin bahan serat dari kelima tingkatan serat pada Tabel 6 hampir sama dengan kadar lignin serat kayu meranti merah dan lebih besar sedikit dari serat kayu daun jarum. Kadar lignin serat pada papan partikel sangat mempengaruhi terhadap kekuatan papan partikel yang dihasilkan. Menurut Hartoyo, (1989) cit Suri, (2002) mengatakan lignin adalah komponen yang tidak diinginkan dalam pembuatan papan partikel, karena mengakibatkan pengaruh buruk terhadap ikatan antar serat dan kekuatan papan partikel. Sehingga dalam pembuatan papan partikel kandungan lignin pada bahan baku serat harus sekecil mungkin/dihilangkan. Dengan demikian serat mekanis yang dihasilkan dari mesin pengurai seperti pada Tabel 6 kadar ligninnya masih rendah.

\section{KESIMPULAN}

Pada pengujian kinerja mesin pengurai yang dilakukan, kapasitas mesin sangat ditentukan oleh kekuatan bahan batang pengurai dan pelat penahan (counter blade), kadar air TKKS cacahan, putaran mesin dan kecepatan pemasukan bahan TKKS cacahan.

Persentase jumlah serat dan serat campuran pada putaran $600 \mathrm{rpm}$ dan 900 rpm tidak berbeda jauh, dari $10 \mathrm{~kg}$ TKKS cacahan pada pengujian 1 dan penguraian 1 didapatkan serat bersih $7,6 \mathrm{~kg}(76 \%)$ dan serat campuran $2,05 \mathrm{~kg}(20 \%)$ dan $0,35 \mathrm{~kg}$ $(3,5 \%)$ sisa dimesin dan menjadi debu.
Begitu juga penguraian pada putaran 900 $\mathrm{rpm}$, didapatkan serat bersih 7,2 kg (72\%), serat campuran $1,2 \mathrm{~kg}(12 \%)$ dan $1,6 \mathrm{~kg}$ $(16 \%)$ sisa dimesin dan menjadi debu.

Persentase serat berdasarkan panjang pada putaran $600 \mathrm{rpm}$ yaitu serat panjang $>10 \mathrm{~cm}(4,6 \%)$, serat menengah $5-10 \mathrm{~cm}$ $(32,2 \%)$ dan serat pendek $2-4 \mathrm{~cm}(61,4 \%)$, sedangkan pada putaran $900 \mathrm{rpm}$ persentase serat panjang $0 \%$, serat menengah $22,37 \%$ dan serat pendek $77,3 \%$.

Dari hasil pengujian mesin pengurai serat TKKS pada putaran $600 \mathrm{rpm}$ dan 900 rpm maka didapatkan 5 macam komposisi tingkatan serat yaitu, a) serat bersih 600 rpm, b) serat bersih $900 \mathrm{rpm}, \mathrm{c}$ ) serat campuran (serat menengah 2-3 cm+kelopak, d) serat campuran (serat pendek $<2 \mathrm{~cm}+$ kelopak), e) serat campuran (serat halus + serbuk).

Dari hasil analisis kimia, ke 5 tingkatan serat tersebut bisa digunakan sebagai bahan baku papan partikel karena kadar lemak, kadar ekstraktif, dan ligninnya yang rendah. Kadar lemaknya kecil dari $3 \%$, dan kadar holoselulosa dan selulosa yang tinggi. Kandungan kimia ke lima tingkatan serat TKKS tersebut dibandingkan dengan serat kayu daun jarum dan kayu daun lebar hampir sama atau tidak berbeda jauh.

\section{SARAN}

Perlu adanya pengujian mesin pengurai dengan beberapa jenis bahan batang pengurai dan pelat penahan. Karena kekuatan batang pengurai dan pelat penahan sangat menentukan kapasitas dan kemampuan mesin untuk menguraikan serat.

Perlu di lakukan penguraian TKKS cacahan dengan beberapa tingkatan kadar air. Serat dengan kadar air yang tinggi strukturnya lunak, sehingga memudahkan proses penguraian. Begitu juga perlu dilakukan pengujian karakteristik mekanik serat TKKS seperti Bulk Density dan kekuatan tarik serat, agar dapat dibandingkan dengan bahan serat alam lainnya. 


\section{DAFTAR PUSTAKA}

Dirjen Perkebunan. 2011. Statistik perkebunan kelapa sawit Indonesia 2009-2011.

Hadi Suryanto, Adjar Pratoto, dan Anwar Kasim. 2001. Pengembangan dan optimasi prototype mesin pengolah limbah tandan kosong sawit untuk menghasilkan serat mekanis. Laporan Kemajuan RUK Tahun II.

Haygreen, J.G. and Bowyer, J.L. 1993. Forest products and wood science an introduction. The lowa State University Press, Ames. IOWA

Kasim, A., Aisman, F. Kasim. 2002. Uji keefectifan effective microorganism 4 (EM-4) pada delignifikasi tandan kosong sawit pada beberapa tingkat konsentrasi inokulum dan lama fermentasi. Jurnal Penelitian Andalas No. 38/Mei/Tahun XIV. Terakreditasi.

Kasim, A. 2009. Proses pembuatan papan partikel dari tandan kosong kelapa sawit dengan perekat berbahan baku gambir. Paten Nomor Pendaftaran 00200900127.

Kasim, A. 2011. Proses produksi dan industri hilir gambir. Andalas University Press. Padang.

Kep Men LH No 13/MENLH/III/1995. Baku Mutu Emisi Sumber Tidak Bergerak.

Propatria, Y. 2000. Pengaruh ukuran serat tandan kosong sawit pada beberapa komposisi serat dengan semen terhadap sifat fisis dan mekanis eternit. Skripsi. Fakultas Pertanian, Universitas Andalas, Padang
Sularso. 1987. Dasar perencanaan dan pemilihan elemen mesin edisi Ke-6. PT. Pradnya Paramita, Jakarta.

Subianto, B. 2003. Pemanfaatan serat tandan kosong kelapa sawit untuk papan partikel dengan perekat penol formaldehid. UPT Balai Litbang Biomaterial-LIPI. Jakarta.

Subianto, B. 2006. Pembuatan papan partikel berukuran komersial dari limbah tandan kosong kelapa sawit dengan perekat urea formaldehid. Jurnal IImu dan Teknologi Kayu Tropis Vol. 3-No. 1. Hal. 9-14.

Suri, M. 2002. Studi penggunaan beberapa perekat untuk pembuatan papan partikel hasil biodelignifikasi tandan kosong kelapa sawit (TKKS) menggunakan EM-4. Tesis. Pascasarjana Universitas Andalas Padang.

Sutigno, P. 1988. Perekat dan perekatan. Departemen Kehutanan Bogor.

Syamani, F.A., Subyakto, Ismail, B., dan Bambang, S. 2006. Studi kelayakan pembuatan pabrik papan partikel berbahan baku serat alam. UPT Balai Litbang Biomaterial - LIPI

Umi Fathanah, Sofyana. 2013. Pembuatan papan partikel (Particle Board) dari tandan kosong sawit dengan perekat kulit akasia dan gambir. Jurnal Rekayasa Kimia dan Lingkungan Vol. 9, No 3, hal 137-143 ISSN 1412-5064. 